\title{
Towards a legal strategy fitting today's challenge of reducing impacts of subsidence in the Netherlands
}

\author{
Martijn van Gils ${ }^{1}$, Esther Stouthamer ${ }^{2}$, and Frank Groothuijse ${ }^{1}$ \\ ${ }^{1}$ Utrecht Centre for Water, Oceans and Sustainability Law, Utrecht University, \\ Utrecht, $3584 \mathrm{BH}$, the Netherlands \\ ${ }^{2}$ Department of Physical Geography, Utrecht University, Utrecht, 3584 CB, the Netherlands \\ Correspondence: Esther Stouthamer (e.stouthamer@uu.nl)
}

Published: 22 April 2020

\begin{abstract}
Land subsidence in the Netherlands is an ongoing process. An increasing number of people and economic assets are exposed to subsidence and damage costs are soaring. In some areas tipping points have already been reached, where current land-use can no longer be maintained without considerable costs.

A specific policy focusing on subsidence is lacking. Dealing with the societal impacts of subsidence is mainly the (implicit) responsibility of the public authorities that regulate the drivers of subsidence. As the societal impacts continue to occur and are increasing, discussions arise on the exact drivers of subsidence and responsibilities for the impacts on society.

Our study aims to analyse whether and to what extent public decision-making, which controls land subsidence due to groundwater-table lowering and extraction of hydrocarbons and its societal impacts, is organised effectively to reduce these societal impacts, and how the legal framework can be improved to achieve that. By studying the respective legal frameworks of these drivers, we map legal solutions for mitigation of subsidence itself or adaptation to its societal impacts - both eventually aimed at reducing the societal impacts of subsidence. In this paper, we focus on the legal framework of one of these drivers: groundwater-table lowering.
\end{abstract}

\section{Human drivers of subsidence}

The Netherlands has a long history of subsidence (Van de Ven, 1993; Vos and Van Heeringen, 1997; Erkens et al., 2016). Large-scale drainage of the extensive peatlands in the western and northern parts of the Netherlands started approximately 1000 years ago as a result of rapid population growth (Borger, 1992; Van Dam, 2001). Subsidence nowadays is still ongoing due to (1) continuous drainage of the former peatland, which is now mainly in use as agricultural land and built-up area, (2) expansion of the built-up area and the infrastructural network, (3) salt mining and the extraction of gas in the northern Netherlands (Fig. 1). As a result of this, currently $\sim 50 \%$ of the coastal-deltaic plain of the Netherlands is located below sea level (Koster et al., 2018).

\section{Land subsidence from a legal perspective: legal control of human drivers}

Law is aimed at regulating human behaviour and is therefore an effective means to prevent human-induced land subsidence. In order to evaluate the legal framework concerning the lowering of the groundwater table, this paper first gives a short overview of the Dutch legal system and public policymaking and decision-making in the Netherlands.

\subsection{The Dutch legal system: constitutional organisation}

The Netherlands has a multilevel administration. Four geographically demarcated levels of government can be distinguished (Fig. 2): the national government, the provinces, the municipalities, and the regional water authorities. Provinces and municipalities are decentralised administrative authorities that have general rule-making competences, which means that they can make rules on a whole range of policy 


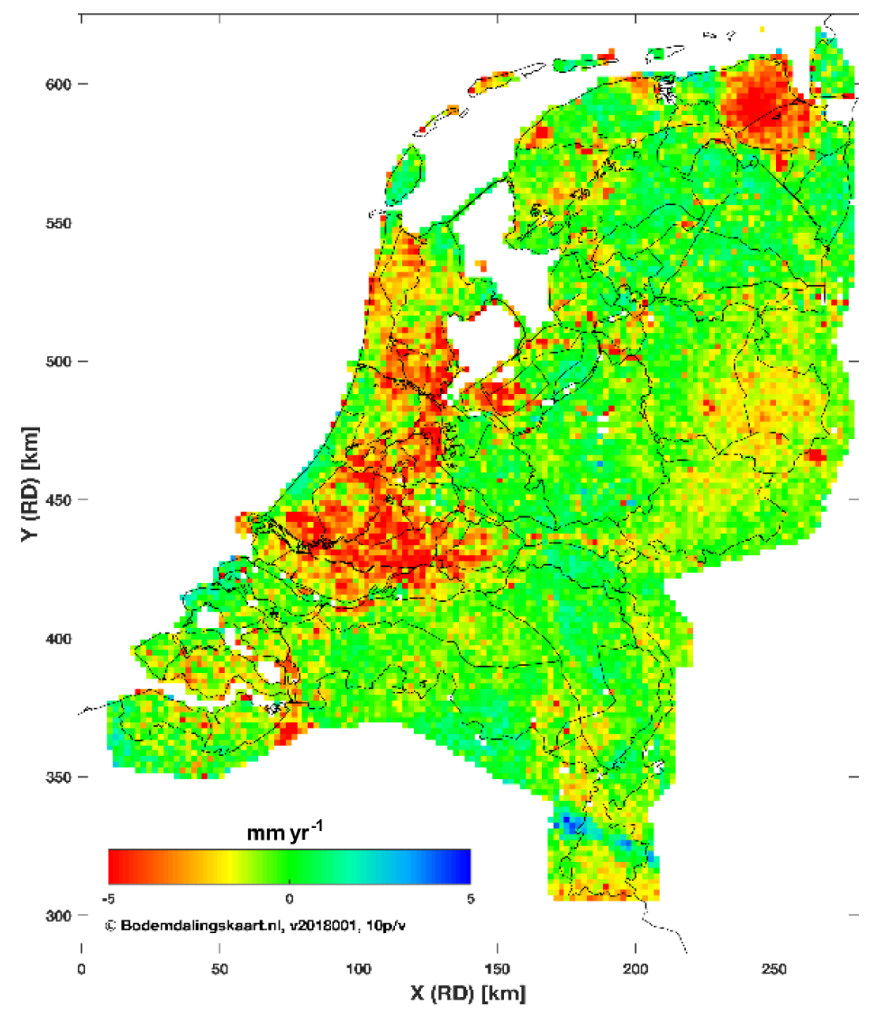

Figure 1. Subsidence map of the Netherlands (ㄷ Bodemdalingskaart.nl, 2018).

areas. They also have executive powers, which means that they are responsible for implementing and enforcing general rules, mostly by making binding decisions in individual cases. The fourth geographically demarcated, decentralised level of government is the Regional Water Authority (RWA). In contrast to the other decentralised administrative authorities, the RWAs can only exercise their competences to deal with one policy area: water management.

The rationale of the multilevel character of the Dutch government is that rules and decisions are best made at the most appropriate level of administration: some issues are better dealt with by the national government since they concern the entire country, while local issues are best dealt with by a municipality.

\subsection{The Dutch legal system: public policy-making and decision-making}

The national government as well as the decentralised administrative authorities use their competences to develop and implement public policy. Policies are not legally binding; instead, they inform these public authorities when they enact general rules or make binding decisions. The adjective "public" means that in enacting general rules and binding decisions public (administrative) authorities ought to pursue public, rather than personal goals. Citizens affected by a public decision can seek judicial protection against such a decision before administrative courts and, on occasion, civil courts if they perceive the decision as unlawful.

The Dutch Constitution lists several public responsibilities that require the government to develop public policies. One example is article 21 of the Constitution, which states that "[i]t shall be the concern of the authorities to keep the country habitable and to protect and improve the environment". The public policies developed to protect the environment are enacted in sectoral laws (Fig. 3), each of which deals with a particular aspect of environmental protection (e.g. spatial planning, water quality, nature protection).

These sectoral laws grant the central government and decentralised public administrative authorities rule-making and executive competences in order to protect different aspects of the environment. These governments must exercise these competences in light of the particular aspect of the environment that a sectoral law aims to protect. As a result, administrative authorities, when taking a binding decision in an individual case for which they must weigh different, sometimes conflicting interests against each other, can only take into account those interests relating to the particular aspect of the environment that the sectoral law deals with. This often results in complex decision-making, since one activity can potentially harm different aspects of the environment and is therefore often regulated in several sectoral laws, for which often different administrative authorities are the competent decision-makers and different interests must be taken into account. Public decision-making in environmental law does therefore seldom take place in isolation - there often is an interplay or interdependency between the different public decisions applicable to an activity. This does not only result in complex decision-making, but also makes it very complex for citizens who seek judicial protection, as responsibility for drainage activities is scattered throughout different laws and regulations executed by different authorities.

Although the sectoral laws will be put together in the Environmental and Planning Act (likely in 2021), this will likely have no or little effect on the fragmented nature of environmental regulation and decision-making.

\section{Lowering of groundwater levels: the legal framework of water-level government}

Human-induced subsidence can either be the result of external pressure of infrastructure and buildings (loading), (largescale) groundwater extractions and water-level management of both groundwater and surface water bodies. In this paper we focus on the legal framework of one of these causes, namely water-level management. 


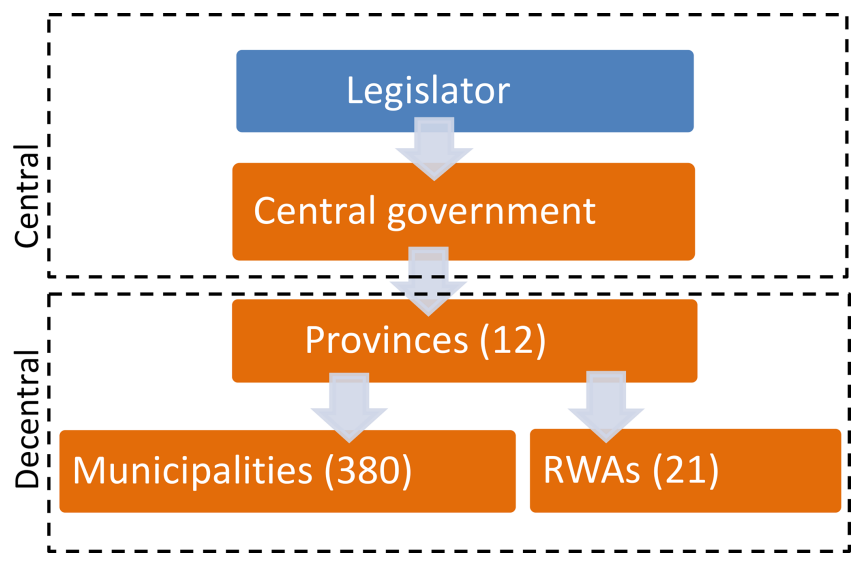

Figure 2. Constitutional organisation of the government in the Netherlands.

\subsection{Public decisions and relevant interests under the legal framework}

The legal framework concerning water-level management primarily consists of two acts, namely the Water Act and the Spatial Planning Act (SPA). The purpose of the Water Act is ensuring water safety, protecting water quality and allowing water systems to fulfil societal functions (Sect. 1.2 "Water Act"). The Water Act designates decision-making competences to different public authorities, relating to the purposes of the Act, including establishing formal decisions with regard to target levels for (designated) groundwater and surface water bodies. RWAs establish water level target decisions for regional waters, which they have to maintain as much as possible. RWAs can do this for instance by operating pump stations and weirs, but they can also exercise their legal water management competences by, for example, regulating (human) activities that can affect water levels (in permits or binding rules).

When establishing water level target decisions, the competent public authority must take into account all interests relevant to this decision. The interests concerning spatial functions that require a certain water level - such as agriculture, nature, residential area, leisure and archaeology - play an important role in this matter. RWAs tend to follow the policy principle "water level follows allocated (spatial) function" when establishing water level target decisions.

Some spatial functions require different groundwater levels; for example, lower groundwater levels are more beneficial to agriculture, whereas higher groundwater levels are more beneficial to nature. For this reason, RWAs are inclined to set lower water levels in water target decisions for areas that have an agricultural function in comparison to the water levels set for areas that have an ecological function in the zoning plan.

Spatial functions have to be allocated to lands by the municipalities in their zoning plans. The Spatial Planning Act

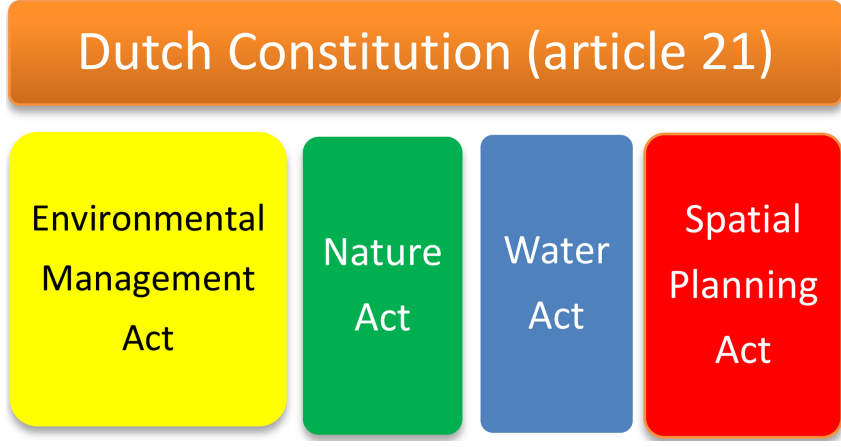

Figure 3. Sectoral environmental protection legislation.

(SPA) requires municipalities to adopt binding zoning plans for all lands under their jurisdiction, including the subsoil, groundwater and surface water. The purpose of the SPA is to provide "good spatial planning" (Sects. 2.1 and 3.1 "SPA"). When adopting a zoning plan, municipalities must therefore take into account all the relevant interests related to good spatial planning. Since providing good spatial planning is an open-ended purpose, a wide variety of interests might be relevant.

The water level set in a water level target decision is therefore closely connected to the spatial functions allocated in the relevant zoning plan.

\subsection{Land subsidence and its societal impact as a relevant interest}

In both the Water Act and the SPA, land subsidence is not explicitly mentioned as an interest that must be taken into account in public decision-making. However, the openendedness of the purposes of both the Water Act and the SPA means that a wide variety of societal impacts of land subsidence can be taken into account in decisions taken under these Acts, such as water level target decisions and zoning plans. The public authorities, however, must weigh those interests against many other relevant interests. The outcome of this balancing exercise is not predictable as a plethora of interests could come into play.

However, for the RWAs, that generally follow the selfbinding policy principle "water level follows allocated function", the spatial functions allocated in a zoning plan are a predominant factor when establishing a water level target decision.

Municipalities can take land subsidence into account when adopting zoning plans, as long as it is connected to good spatial planning. There are two procedural requirements that see to a zoning plan's effects on groundwater levels: the municipality must describe how it has taken into account the effects of the zoning plan on local water management, and the municipality must consult with the local RWA for the effects of the plan on groundwater levels. However, these are pro- 
cedural rather than substantive requirements - they do not prescribe how land subsidence should be taken into account in a zoning plan.

\section{Towards more effective control of groundwater-level lowering: improving the legal framework}

The Dutch legal system can be characterised as a multilevel administration, designed to function at different geographical scales. For that reason, the level of government that corresponds with the geographical scales at which the impacts of the decision are felt, establish general rules and take binding decisions. Furthermore, these different levels of government each are competent to adopt rules and take decisions to protect particular aspects of the environment (spatial planning, water, etc), rather than the environment as a whole.

These characteristics of the Dutch legal system, however, seem weaknesses when it comes to effective control of groundwater-level lowering. Impediments to its effective control are the lack of a specific policy focusing on land subsidence and the fragmentation of decision-making between various different public authorities. This results in incoherent, and hence ineffective, public decision-making. Whether and to what extent groundwater levels are lowered, depends on the water levels set in water level target decisions by the RWAs, which in turn depend on the spatial functions allocated in the municipal zoning plans. Although the societal impacts of land subsidence can be a relevant interest to be taken into account in a zoning plan (as long as it relates to good spatial planning), municipalities have to balance this interest against other spatial interests such as agriculture. Some municipalities might thus design their zoning plan in such a way that it reduces the impacts of land subsidence in vulnerable areas, such as allocating bodies of water and the surrounding land a nature function, rather than agricultural area or establishing building bans or prescribe adaptive building requirements in subsidence vulnerable areas; others might not do so.

One way to improve the existing legal framework, so that specific policies focusing on land subsidence can be developed, would be to explicitly address land subsidence in sectoral laws, such as the SPA and the Water Act, and require its effects to be explicitly weighed in decisions under these sectoral laws.

Another way to improve the legal framework would be to stimulate provinces to take their policy-steering and regional coordination role seriously by using their legal instruments to coordinate municipal spatial planning policy and decisions and water management policy and decisions of the RWAs. Provinces are in a uniquely suitable position to develop and implement policies to prevent or mitigate the impacts of land subsidence. First, because provincial interests correspond to the geographical scale of the societal impacts of land subsi- dence. The impacts of land subsidence are felt in areas larger than individual municipalities and RWAs but only in certain provinces - not in the entire country (Fig. 1). Provinces therefore seem the appropriate level of government to develop coherent policies to reduce the impacts of subsidence, as it is in the provincial interest to do so. Second, they can already coordinate decision-making on regional spatial planning and regional water management in the provinces and can thus develop specific (regional) policies on land subsidence.

Finally, structural monitoring by the national government could result in more coherent policy-making and decisionmaking. Impartial and publicly accessible current data on e.g. surface elevation, groundwater levels and subsurface properties, preferably standardized and at sufficient spatial and temporal resolution, can help public authorities develop more informed policies and take better decisions, for example when allocating functions in a zoning plan.

In the end, however, it is not the lawyers or geologists that reduce the impacts of land subsidence: that depends on good public policy-making and decision-making by the public authorities, informed by geological information and laid down in legal rules. Improvements to the legal framework, however, can contribute to informed political decision-making and the development of specific policies by public authorities, and thus to more effective decision-making in order to reduce the societal impacts of land subsidence.

\section{Conclusions}

Law is aimed at regulating human behaviour and is therefore an effective means to prevent the impacts of human-induced soil subsidence. The Duth legal system is a multilevel administration, with each level of government functioning at different geographical scales and exercising competences on different aspects of the environment. These characteristics, however, are weaknesses when it comes to effective control of soil subsidence. The lack of specific policy focusing on soil subsidence and the fragmentation of competences results in ineffective public decision-making. Improvements to the legal framework and better use of existing legal instruments, such as strengthening the coordinating and policysteering role of provinces, could improve the effectiveness of decision-making to reduce the impacts of subsidence.

Data availability. This is a legal research paper and therefore, no empirical data sets have been used. The article is based on the review of statutory law and legal literature, to which references are included in the article.

Author contributions. The legal analysis in Sects. 2 and 3 of this article is written by FG and MvG; ES has written Sect. 1, in which subsidence and the human drivers thereof are described. Section 4 , in which suggestions for improving the legal framework are pre- 
sented, and Sect. 5, the conclusion, are jointly written by the authors.

Competing interests. The authors declare that they have no conflict of interest.

Special issue statement. This article is part of the special issue "TISOLS: the Tenth International Symposium On Land Subsidence

- living with subsidence". It is a result of the Tenth International Symposium on Land Subsidence, Delft, the Netherlands, 17-21 May 2021.

Financial support. This research has been supported by Utrecht University (seed money grant, focus area Future Deltas).

\section{References}

Borger, G. J.: Draining-digging-dredging; the creation of a new landscape in the peat areas of the low countries, in: Fens and bogs in the Netherlands: vegetation, history, nutrient dynamics and conservation, edited by: Verhoeven, J. T. A., Geobotany, 18, 31-172, 1992.

Erkens, G., van der Meulen, M. J., and Middelkoop, H.: Double trouble: subsidence and $\mathrm{CO}_{2}$ respiration due to 1,000 years of Dutch coastal peatlands cultivation, Hydrogeol. J., 24, 551-568, 2016.
Koster, K., Stafleu, J., Cohen, K. M., Stouthamer, E., Busschers, F. S., and Middelkoop, H.: 3D distribution of organic matter in coastal-deltaic peat: implications for subsidence and $\mathrm{CO}_{2}$ emissions by human induced peat oxidation, Anthropocene, 22, 1-9, 2018.

Nehmelman, R.: Institutional and governance aspects of water management: subsidiarity and decentralisation - the Dutch approach, Water Law, 24, 134-140, 2015.

Reinhard, S. and Folmer, H. (Eds.): Water policy in the Netherlands. Integrated Management in a densely populated delta, in: Resources for the Future (RFF), 1-14, 2009.

Van Dam, P. J. E. M.: Sinking peat bogs, Environmental change in Holland 1350-1550, Environmental History, 1, 32-46, 2001.

Van de Ven, G. P.: Leefbaar laagland [Liveable lowlands], Uitgeverij Matrijs, Utrecht, The Netherlands, 455 pp., 1993.

Van Doorn-Hoekveld, W. J.: Distributional Effects of EU Flood Risk Management and the Law, chap. 3, 2017.

Van Rijswick, H. F. M. W. and Havekes, H. J. M.: European and Dutch Water Law, Europa Law Publishing, chaps. 7 and 10 , 2012.

Vos, P. C. and Van Heeringen, R. M.: Holocene geology and occupation history of the province of Zeeland, Mededelingen NITG/TNO, 59, 5-109, 1997. 